\title{
Synthesis of Bimetallic Copper-Rich Nanoclusters Encapsulating a Linear Palladium Dihydride Unit
}

\author{
Kiran Kumarvarma Chakrahari, Rhone P. Brocha Silalahi,Tzu-Hao Chiu, Xiaoping Wang, Nadia \\ Azrou,Samia Kahlal, Yu-Chiao Liu, Ming-Hsi Chiang, Jean-Yves Saillard, ${ }^{*}$ and C. W. Liu*
}

Dedication:

\begin{abstract}
The structurally precise Cu-rich hydride nanoclusters $\left[\mathrm{PdCu}_{14} \mathrm{H}_{2}(\mathrm{dtc} / \mathrm{dtp})_{6}(\mathrm{C} \equiv \mathrm{CPh})_{6}\right]$ (dtc: di-butyldithiocarbamate(1); dtp: di-isopropyl dithiophosphate(2)) were synthesized from the reaction of polyhydrido copper clusters $\left[\mathrm{Cu}_{28} \mathrm{H}_{15}\left(\mathrm{~S}_{2} \mathrm{CN}^{n} \mathrm{Bu}_{2}\right)_{12}\right]^{+}$or $\left[\mathrm{Cu}_{20} \mathrm{H}_{11}\left\{\mathrm{~S}_{2} \mathrm{P}\left(\mathrm{O}^{\prime} \mathrm{Pr}\right)_{2}\right\}_{9}\right]$ with phenyl acetylene in the presence of $\mathrm{Pd}\left(\mathrm{PPh}_{3}\right)_{2} \mathrm{Cl}_{2}$. Their structures and compositions were determined by single crystal $\mathrm{X}$-ray diffraction and the results were supported by ESI-mass spectrometry. Hydride positions in 1 were confirmed by single crystal neutron diffraction. Each hydride is connected to one $\mathrm{Pd}(0)$ and four $\mathrm{Cu}(\mathrm{I})$ atoms in slightly distorted trigonalbipyramidal geometry. The anatomies of clusters $\mathbf{1}$ and $\mathbf{2}$ are very similar and DFT calculations allow rationalizing the interactions between the encapsulated $\mathrm{PdH}_{2}$ unit and its $\mathrm{Cu}_{14}$ bicapped icosahedral cage. As a result, $\mathrm{Pd}$ has the highest coordination number (14) so far recorded.
\end{abstract}

Atomically precise bimetallic nanoclusters (NCs) have emerged as a new class of nanomaterials. ${ }^{[1]}$ Numerous studies have shown that doping NCs with foreign atoms allows tuning their properties, thus broadening their field of applications. ${ }^{[2]}$ For instance, bimetallic clusters have been found to exhibit an increase in the photoluminescence quantum yield, ${ }^{[3]}$ enhanced catalytic performance and stability compared to their homometallic counterparts. ${ }^{[4]}$ In particular, bimetallic systems made of group 10 metals $(\mathrm{Pt}, \mathrm{Pd}$, or $\mathrm{Ni}$ ) and "host metals" like $\mathrm{Cu}$ have been used in many catalytic processes. ${ }^{[5-9]}$ Subnanometer $\mathrm{Cu}-\mathrm{Pd}$ oxide clusters were also used as catalysts. ${ }^{[10]}$ The geometry, electronic properties, and active sites of copper clusters doped with $\mathrm{Pd}$ atoms, $\mathrm{PdCu}_{n-1}(n=2-6)$, were alsotheoretically investigated. ${ }^{[11]}$

[*] Dr. K. K.Chakrahari, R. P. B. Silalahi, T.-H. Chiu, Prof. C. W. Liu Department of Chemistry, National Dong Hwa University

No. 1, Sec. 2, Da Hsueh Rd.

Shoufeng, Hualien 97401 (Taiwan R.O.C.)

E-mail: chenwei@mail.ndhu.edu.tw

Homepage: http://faculty.ndhu.edu.tw/ cwl/index.htm

Dr. K. K.Chakrahari,

Department of Chemistry, SRM Institute of Science and Technology, Kattankulathur 603203, India

Dr. X. Wang

Neutron Scattering Division, Neutron Sciences Directorate, Oak Ridge National Laboratory, Oak Ridge, TN, 37831, USA

Nadia Azrou, Dr. S. Kahlal, Prof. J.-Y. Saillard

Univ Rennes, CNRS, ISCR - UMR 6226, F-35000 Rennes, France

E-mail: jean-yves.saillard@univ-rennes1.fr

Dr. Y.-C. Liu, Dr. M.-H. Chiang

Institute of Chemistry, Academia Sinica

Taipei-11528, Taiwan (R.O.C.)

Supporting information for this article is available on the WWW under http://dx.doi.org/xx.xxxx/anie.xxxxxxxxx.
Structurally precise alloy NCs were produced from the doping by $\mathrm{Pd}, \mathrm{Pt}, \mathrm{Cu}, \mathrm{Ag}, \mathrm{Cd}$ and $\mathrm{Hg}$ of silver and gold species such as $\mathrm{Ag}_{20}\left[\mathrm{~S}_{2} \mathrm{P}(\mathrm{OR})_{2}\right]_{12}, \quad \mathrm{Ag}_{21}\left[\mathrm{Se}_{2} \mathrm{P}(\mathrm{OR})_{2}\right]_{12}, \quad \mathrm{Ag}_{25}(\mathrm{SR})_{18}$, $\mathrm{Ag}_{44}(\mathrm{SR})_{30}{ }^{4-}, \quad \mathrm{Au}_{25}(\mathrm{SR})_{18}, \quad \mathrm{Au}_{38}(\mathrm{SR})_{24}$ and $\mathrm{Au}_{144}(\mathrm{SR})_{60} .^{[12-16]}$ Interestingly, there are no reportso far of atomically precise copper clusters doped with group 10 metals.

Recently, we reported the synthesis of copper-rich bimetallic $\mathrm{NCs},\left[\mathrm{M} @ \mathrm{Cu}_{12}(\mathrm{dtc})_{6}(\text { alkynyl })_{4}\right]^{+}(\mathrm{M}=\mathrm{Ag}, \mathrm{Au})$, from the template galvanic exchange strategy of reacting $\left[\mathrm{Cu}_{13}(\mathrm{dtc})_{6}(\text { alkynyl })_{4}\right]^{+}$with corresponding metal salts. ${ }^{[3 \mathrm{~b}]} \mathrm{A}$ similar synthetic strategy in inserting group 10 metals into the 2-electron copper superatom was not successful. In this study, we isolated a family of Cu-Pd hydride clusters from a novel synthetic protocol of reacting copper hydrides with alkynes in the presence of $\mathrm{Pd}(\mathrm{II})$ salt. Interestingly, our results also provide the first evidence of a linear $\left[\mathrm{PdH}_{2}\right]^{2-}$ species embedded within a $\mathrm{Cu}(\mathrm{I})$ cage. This is the first "molecular" example consisting of a unique 14-electron anionic complex, originally identified in the solid-state ternary hydride $\mathrm{Na}_{2} \mathrm{PdH}_{2}{ }^{[18]}$

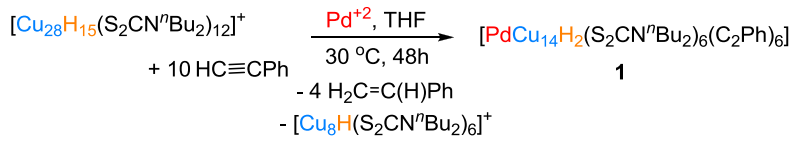

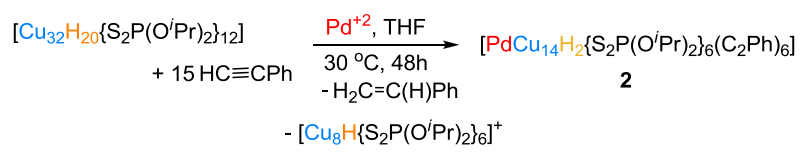

Scheme 1. Synthesis of compounds 1 and 2.

In a typical experiment, to a THF suspension of equimolar $\left[\mathrm{Cu}_{28} \mathrm{H}_{15}\left(\mathrm{~S}_{2} \mathrm{CN}^{n} \mathrm{Bu}_{2}\right)_{12}\right] \mathrm{PF}_{6}{ }^{[19 a]}$ and $\left[\mathrm{Pd}\left(\mathrm{PPh}_{3}\right)_{2} \mathrm{Cl}_{2}\right]$, a ten-fold excess of phenyl acetylene was added and the reaction mixture was stirred at $30^{\circ} \mathrm{C}$ for 48 hours. The colour of the suspension changed from red to dark brown. Workup of this mixture leads to the isolation of $\left[\mathrm{PdCu}_{14} \mathrm{H}_{2}\left(\mathrm{~S}_{2} \mathrm{CN}^{n} \mathrm{Bu}_{2}\right)_{6}(\mathrm{C} \equiv \mathrm{CPh})_{6}\right]\left(\mathbf{1}_{\mathrm{H}}\right)$ as dark red powder in $54 \%$ yield. The reaction also yielded styrene and $\left[\mathrm{Cu}_{8} \mathrm{H}\left(\mathrm{S}_{2} \mathrm{CN}^{n} \mathrm{Bu}_{2}\right)_{6}\right]^{+}$as byproducts. ${ }^{[19]}$ The hydrogen gas released from the reaction of terminal alkyne's acidic hydrogen with the hydrides of $\left[\mathrm{Cu}_{28} \mathrm{H}_{15}\left(\mathrm{~S}_{2} \mathrm{CN}^{n} \mathrm{Bu}_{2}\right)_{12}\right]^{+}$is assumed to be the reductant for the partial conversion of alkyne into alkene (four out of ten equivalents of phenyl-acetylene were reduced to styrene) and $\mathrm{Pd}(\mathrm{II})$ to $\mathrm{Pd}(0)$. The di-isopropyl dithiophosphate (dtp) analogue of $\mathbf{1}$ was isolated from the reaction of $\left[\mathrm{Cu}_{20} \mathrm{H}_{11}\left\{\mathrm{~S}_{2} \mathrm{P}\left(\mathrm{O}^{\prime} \mathrm{Pr}\right)_{2}\right\}_{9}\right]^{[19 \mathrm{~b}]}$ or $\left[\mathrm{Cu}_{32} \mathrm{H}_{20}\left\{\mathrm{~S}_{2} \mathrm{P}\left(\mathrm{O}^{\prime} \mathrm{Pr}\right)_{2}\right\}_{12}\right]^{[19 \mathrm{~d}]}$ with excess of phenylacetylene in the presence of $\left[\mathrm{Pd}\left(\mathrm{PPh}_{3}\right)_{2} \mathrm{Cl}_{2}\right]$ (Scheme 1). The structures were established by both single crystal X-ray and Neutron diffraction. The presence of two hydrides is further confirmed by the isolation of their deuterium 
analogues $\quad\left[\mathrm{Cu}_{14} \mathrm{PdD}_{2}\left(\mathrm{~S}_{2} \mathrm{CN}^{n} \mathrm{Bu}_{2}\right)_{6}\left(\mathrm{C}_{2} \mathrm{Ph}\right)_{6}\right] \quad\left(\mathbf{1}_{\mathrm{D}}\right) \quad$ and $\left[\mathrm{Cu}_{14} \mathrm{PdD}_{2}\left\{\mathrm{~S}_{2} \mathrm{P}\left(\mathrm{O}^{\prime} \mathrm{Pr}\right)_{2}\right\}_{6}(\mathrm{C} \equiv \mathrm{CPh})_{6}\right]$ (2D) which were made from $\left[\mathrm{Cu}_{28} \mathrm{D}_{15}\left(\mathrm{~S}_{2} \mathrm{CN}^{\mathrm{n}} \mathrm{Bu}_{2}\right)_{12}\right]^{+}$and $\left[\mathrm{Cu}_{20} \mathrm{D}_{11}\left\{\mathrm{~S}_{2} \mathrm{P}\left(\mathrm{O}^{\prime} \mathrm{Pr}\right)_{2}\right\}_{9}\right]$, respectively. During the synthesis of $1_{D}$ and $2 \mathrm{D}$, along with monodeuterated styrene $\left[\mathrm{Cu}_{8} \mathrm{D}\left(\mathrm{S}_{2} \mathrm{CN}^{n} \mathrm{Bu}_{2}\right)_{6}\right]^{+}$and $\left[\mathrm{Cu}_{8} \mathrm{D}\left\{\mathrm{S}_{2} \mathrm{P}\left(\mathrm{O}^{\prime} \mathrm{Pr}\right)_{2}\right\}_{6}\right]^{+}$were isolated, respectively, as byproducts. $\mathrm{ESI}$ mass spectrum shows the molecular ion $\left[\mathbf{1}_{\mathrm{H}}\right]^{+}$at $\mathrm{m} / \mathrm{z} 2829.3$ (calcd 2828.6), [1 $\left.\mathbf{1}_{\mathrm{D}}\right]^{+}$at $\mathrm{m} / \mathrm{Z}$ 2831.5 (calcd 2830.7), [2] ${ }^{+}$at $\mathrm{m} / \mathrm{z} 2882.9$ (calcd 2881.2), [2 $\mathrm{D}^{-}$ $\left.\left\{\mathrm{Cu}\left(\mathrm{C}_{2} \mathrm{Ph}\right)\right\}_{2}\right]^{+}$at $\mathrm{m} / \mathrm{z} 2554.4$ (calcd 2554.3), and their simulated isotopic patterns match well with experiment (Figure 1, S1-S3). We have also observed fragment ion peaks corresponding to the loss of $\mathrm{C}_{2} \mathrm{Ph}, \mathrm{Cu}\left(\mathrm{C}_{2} \mathrm{Ph}\right), \mathrm{Cu}\left(\mathrm{C}_{2} \mathrm{Ph}\right)_{2}$ and $\left\{\mathrm{Cu}\left(\mathrm{C}_{2} \mathrm{Ph}\right)\right\}_{2}$.

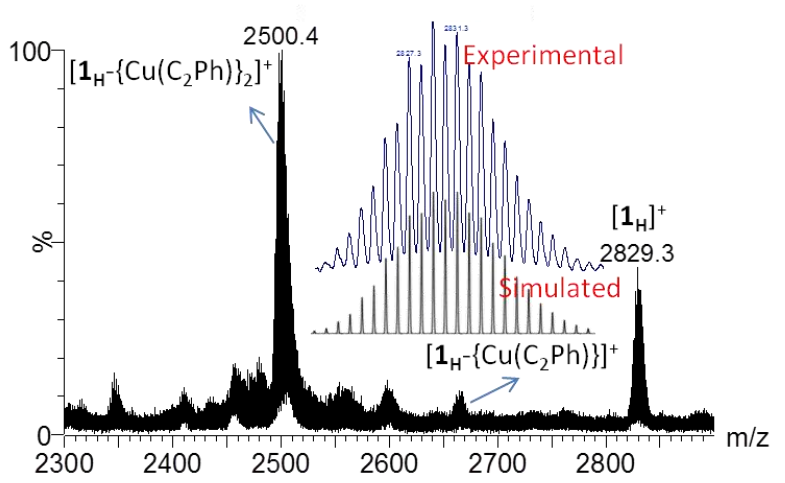

Figure 1. Positive mode ESI-MS of $\left[\mathbf{1}_{\mathrm{H}}\right]^{+}$, . Inset shows experimental and simulated mass spectra.

${ }^{1} \mathrm{H}$ NMR spectroscopic analyses of $\mathbf{1}$ and $\mathbf{2}$ identified one set of acetylide and two sets of alkyl group corresponding to the $\mathrm{dtc} / \mathrm{dtp}$ ligands. Though, compound 2 shows a single ${ }^{31} \mathrm{P}$ NMR resonance at $103.4 \mathrm{ppm}$, the alkyl groups corresponding to the dtp ligands exhibit two sets of ${ }^{1} \mathrm{H}$ resonance (Figure S4, S5). This trend of chemical shifts suggests no two-fold symmetry imposed on the dithiolate ligand environment around the cluster core. The presence of two hydrides in cluster $\mathbf{1}_{\mathbf{H}}$ is confirmed by a ${ }^{1} \mathrm{H}$ NMR resonance peak at $1.90 \mathrm{ppm}$ in $\mathrm{CD}_{2} \mathrm{Cl}_{2}$, which is echoed by the presence of deuteride signal at $1.92 \mathrm{ppm}$ for compound $1_{D}$ in dichloromethane at $203 \mathrm{~K}$ (Figure 2). Similarly, hydride and deuteride resonance for $\left(\mathbf{2}_{\mathrm{H}}, \mathbf{2}_{\mathrm{D}}\right)$ were observed at $(0.49,0.49) \mathrm{ppm}$ in $\left(\mathrm{CDCl}_{3}, \mathrm{CHCl}_{3}\right)$ solvent (Figure S5, S6). Overall compositions of two hydrides, six acetylides and six $\mathrm{dtc}(\mathbf{1}) / \mathrm{dtp}(2)$ were confirmed by the integration of ${ }^{1} \mathrm{H}$ NMR resonances of the newly synthesized clusters. ${ }^{1} \mathrm{H}$ NMR of $1_{D}$ and 2D shows the presence of hydride peaks with an intensity of 0.52 and 0.32 respectively (Figure S7, S8), indicating that the hydrides in 1D and 2D are from both parent cluster and phenylacetylene. Hence the clusters have $74 \%\left(\mathbf{1}_{\mathrm{D}}\right)$ and $84 \%$ (2D) deuterium incorporation.

The single crystal X-ray diffraction analyses of clusters 1 (triclinic) and 2 (monoclinic) indicate they have an identical $\mathrm{PdCu}_{14}$ metal core. Thermal ellipsoid drawings of $\mathbf{1}_{\mathbf{H}}$ and $\mathbf{2}$ are depicted in Figure 3 and selected metrical data from single crystal X-ray and neutron diffraction analyses are given in Table 1. Additional structural diffraction data are listed in Table $\mathrm{S} 1$ and S2. The copper framework can be viewed as a bicapped icosahedron (green) with a $\mathrm{Pd}$ atom at its center (brown). A pseudo-3-fold axis passes through the two capping copper atoms and the central $\mathrm{Pd}$ (Figure $3 \mathrm{c}$ ). Thus, a bicappedcentered icosahedral $\mathrm{PdCu}_{14}$ metallic core of $D_{3 d}$ symmetry is generated. Two additional interstitial hydrides are located along the $C_{3}$ axis on each side of the $\mathrm{Pd}$ atom, as authenticated by the neutron structure of $\mathbf{1}_{\mathrm{H}}$, in which the $\mathrm{Pd}-\mathrm{H}$ distance is found to be rather short $(1.759(14) \AA)$. These two hydrides are located in trigonal-bipyramidal cavities formed by one capping $\mathrm{Cu}$, the corresponding capped $\mathrm{Cu}_{3}$ face and the $\mathrm{Pd}$ atom (Figure $3 \mathrm{~d}$ ). The Cu-H lengths averaged 1.932(18) $\AA$ (Figure S9-S11, Table S3). The resulting $D_{3 d} \mathrm{PdH}_{2} \mathrm{Cu}_{14}$ core is stabilized by six dithiolates and six phenyl acetylides. Half of the alkyl chains corresponding to the $\mathrm{dtc}(\mathbf{1}) / \mathrm{dtp}(2)$ ligands are oriented towards the acetylide ligands, which are arranged along the waist of the $\mathrm{PdCu}_{14}$ core, whereas the remaining half are oriented away from the metal core. This is in full agreement with the above reported NMR spectroscopic results.

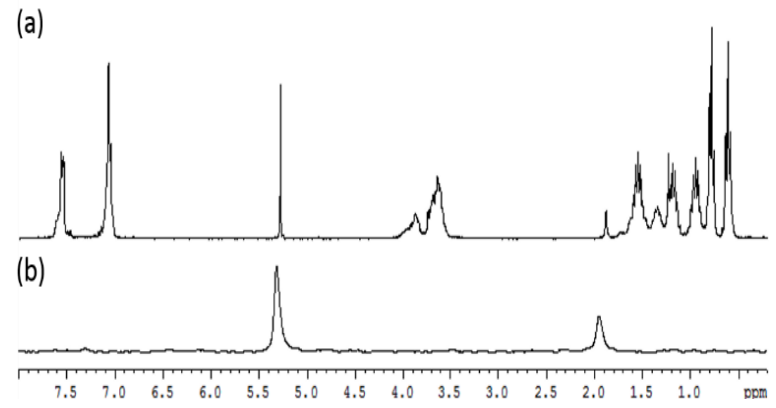

Figure 2. (a) ${ }^{1} \mathrm{H}$ NMR spectrum of compound $\mathbf{1}_{\mathrm{H}}$ in $\mathrm{CD}_{2} \mathrm{Cl}_{2}$ and (b) ${ }^{2} \mathrm{H} \mathrm{NMR}$ spectrum of compound $\mathbf{1}_{\mathrm{D}}$ in $\mathrm{CH}_{2} \mathrm{Cl}_{2}$ solvent.

The inner icosahedral configuration of twelve copper atoms around the central $\mathrm{PdH}_{2}$ unit in $\mathbf{1}$ and $\mathbf{2}$ is similar to that in $\left[P d @ M_{12} @\left\{M_{12}(S R)_{18}\right\}\right]^{2-}(M=A g, A u) .^{[12,14]}$ The bicapped icosahedral core centered with a heterometal was also found in $\mathrm{Ag}_{26} \mathrm{Pt}(2-\mathrm{EBT})_{18}\left(\mathrm{PPh}_{3}\right)_{6}\left(\mathrm{EBTH}=\right.$ ethylbenzenethiol) ${ }^{[20]}$ None of these examples has encapsulated hydrides except clusters 1 and 2.

The six dtc/dtp ligands are equally distributed on the top and bottom of the cluster along the $C_{3}$ axis. Each of the dtc/dtp ligands bridges four metal centres (one capping and three icosahedral copper atoms) in a $\left(\mu_{2}, \mu_{2}\right)$ binding mode. The six acetylide ligands are arranged along the waist of the copper icosahedron, alternatively binding the top and bottom triangles in a $\mu_{3}-\eta^{1}$ fashion. As a result, the $D_{3 d}$ symmetry identified in metal core is reduced to $S_{6}$ symmetry. Being connected to twelve copper and two hydrides, palladium displays a coordination number of 14 , the highest value observed so far.

The dtc supported $\mathrm{PdCu}_{14}$ cluster (1) is reddish, whereas the dtp analogue (2) appears to be violet (inset figure S12). The UVvis spectrum of 1 shows a broad absorption band around 490$560 \mathrm{~nm}$ and an intense one at $287 \mathrm{~nm}$. The dtp analogue (2) shows similar (495-556 $\mathrm{nm}$ ) bands, but with lower intensity in the UV region. The stabilities of $\mathbf{1}$ and $\mathbf{2}$ in dichloromethane at $25^{\circ} \mathrm{C}$ were compared. The absorption spectrum of $\mathbf{2}$ changed steadily over time and it is completely decomposed within 10 hours, whereas 1 requires seven days (Figures S13, S14). 
Table 1. Selected bond lengths $(\AA)$ for $\mathbf{1}_{\mathrm{H}}, \mathbf{1}_{\mathrm{D}}, \mathbf{2}$ (single crystal X-ray), $\mathbf{1}_{\mathrm{H}}{ }^{*}$ (neutron), $\mathbf{1}^{\prime}$ and $\mathbf{2}^{\prime}$ (DFT). Values in brackets are the corresponding computed Wiberg indices.

\begin{tabular}{|c|c|c|c|c|c|c|}
\hline & $\mathrm{Pd}-\mathrm{Cu}_{\mathrm{ico}}$ & $\mathrm{Cu}_{\mathrm{ico}}-\mathrm{Cu}_{\mathrm{ico}}$ & $\mathrm{Cu}_{\text {cap }}-\mathrm{Cu}_{\mathrm{ico}}$ & $\mathrm{Cu}-\mathrm{X}$ & Pd-X & Cu-S \\
\hline$\overline{1_{H}}$ & $2.684(4)-2.785(3)$ & $2.602(7)-3.323(4)$ & $2.565(6)-2.606(5)$ & $1.88(3)-1.93(5)^{\mathrm{a}}$ & $1.84(3)^{\mathrm{a}}$ & $2.271(1)-2.459(8)$ \\
\hline $1_{\mathrm{H}}^{*}$ & $2.694(9)-2.795(6)$ & $2.554-3.324$ & $2.555(10)-2.610(10)$ & $1.875(19)-2.020(16)$ & $1.759(14)^{a}$ & $2.270(2)-2.500(2)$ \\
\hline 1D & $2.687(4)-2.784(5)$ & $2.612(1)-3.3178(8)$ & $2.566(1)-2.613(1)$ & $1.77(4)-2.03(6)^{b}$ & $1.76(2)^{b}$ & $2.266(15)-2.480(15)$ \\
\hline $1^{\prime}$ & $\begin{array}{l}2.736-2.780 \\
{[0.052-0.063]}\end{array}$ & $\begin{array}{l}2.608-3.500 \\
{[0.070-0.016]}\end{array}$ & $\begin{array}{l}2.599-2.620 \\
{[0.070-0.068]}\end{array}$ & $\begin{array}{l}1.937-1.989 \\
{[0.066-0.046]}\end{array}$ & $\begin{array}{l}1.760^{\mathrm{a}} \\
{[0.226]}\end{array}$ & $\begin{array}{l}2.351-2.514 \\
{[0.220-0.114]}\end{array}$ \\
\hline 2 & $2.690(7)-2.800(7)$ & $2.578(7)-3.164(6)$ & $2.680(4)-2.768(5)$ & $1.800(3)-1.850(3)^{\mathrm{a}}$ & $1.80(3)^{\mathrm{a}}$ & $2.267(7)-2.459(7)$ \\
\hline $\mathbf{2}^{\prime}$ & $\begin{array}{l}2.735-2.794 \\
{[0.050-0.075]}\end{array}$ & $\begin{array}{l}2.636-3.264 \\
{[0.058-0.020]}\end{array}$ & $\begin{array}{l}2.691-2.761 \\
{[0.058-0.066]}\end{array}$ & $\begin{array}{l}1.865-1.902 \\
{[0.077-0.068]}\end{array}$ & $\begin{array}{l}1.777^{a} \\
{[0.214]}\end{array}$ & $\begin{array}{l}2.292-2.463 \\
{[0.217-0.126]}\end{array}$ \\
\hline
\end{tabular}

${ }^{\mathrm{a}} \mathrm{X}=\mathrm{H},{ }^{\mathrm{b}} \mathrm{X}=\mathrm{D}$

(a)

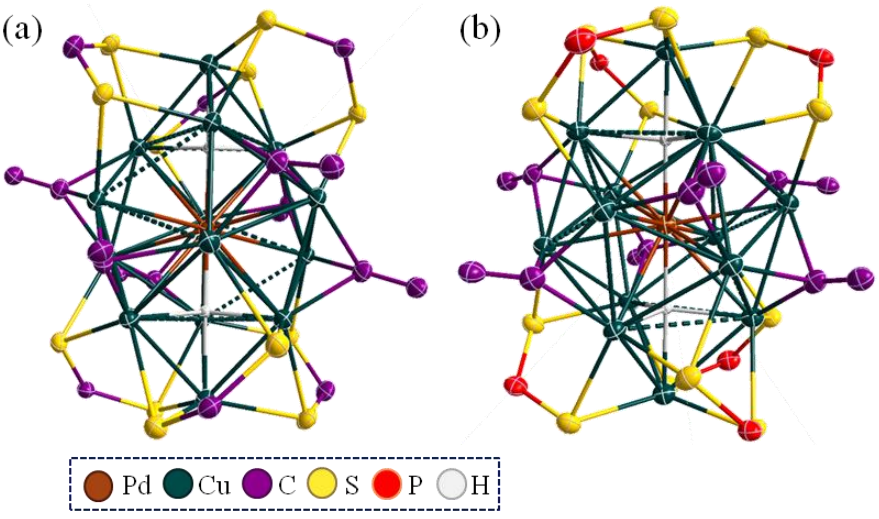

(c)

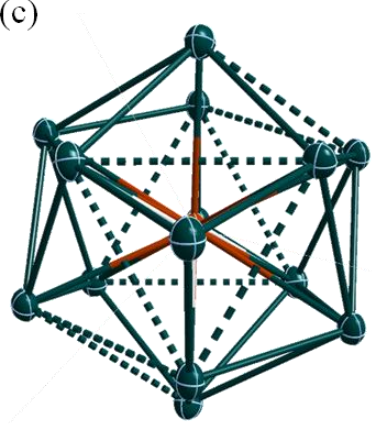

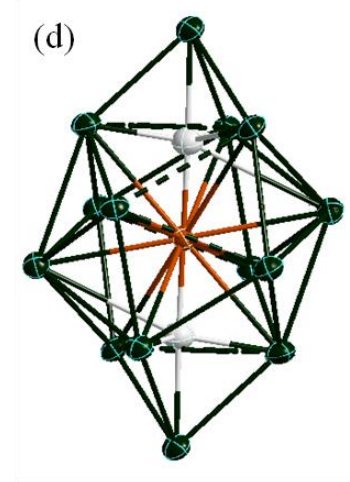

Figure 3. The ORTEP drawing of 1 (a) and 2 (b) with $30 \%$ thermal ellipsoid probability. $\mathrm{N}^{n} \mathrm{Bu}_{2}$ (1), O'Pr (2) and phenyl groups are omitted for clarity. (c) A perspective view along 3-fold axis of $\mathrm{PdH}_{2} \mathrm{Cu}_{14}$ core. (d) Side view of a $\mathrm{PdH}_{2} \mathrm{Cu}_{14}$ core from neutron diffraction data.

Under the same conditions the stabilities of these clusters were also monitored by ESI-Mass spectra using $\left[\mathrm{Cu}_{8} \mathrm{H}(\mathrm{dtc} / \mathrm{dtp})_{6}\right]^{+}$as reference. The results show that $\mathbf{1}_{\mathrm{H}}$ is extremely stable, whereas $\mathbf{1}_{\mathrm{D}}$ loses its intensity with time (Figure $\mathrm{S} 15, \mathrm{~S} 16)$. The results indicate that the replacement of dtc with dtp decreases cluster stability. Both $\mathbf{1}$ and $\mathbf{2}$ display photoluminescence in solid and solution states at $77 \mathrm{~K}$. The emission maximum in 2-methyl tetrahydrofuran (MeTHF) at $77 \mathrm{~K}$ is centred at $623 \mathrm{~nm}$ for $\mathbf{1}$, which is a blue-shift compared to the emission observed for $2(680 \mathrm{~nm})$ with almost equal in intensity (Figure S12). Their emission intensity decreases sharply upon raising the temperature to $177 \mathrm{~K}$ (Figure S17) and the luminescent thermochromism is clearly identified in $\mathbf{2}$ as the emission maximum shifts from 680 at $77 \mathrm{~K}$ to $641 \mathrm{~nm}$ at $277 \mathrm{~K}$.

The photoelectron spectroscopic studies have been used to evaluate the metal oxidation states. X-ray photoelectron spectroscopy (XPS) analysis of $\mathbf{1}_{\mathrm{H}}$ indicates binding energies at 336.0 and $341.0 \mathrm{eV}$ corresponding to $\mathrm{Pd}(0) 3 \mathrm{~d}_{5 / 2}$ and $3 \mathrm{~d}_{3 / 2}$ respectively (Figure S18). The XPS results of 1 fit exactly with the existence of the expected elements.

DFT calculations were performed on simplified models of 1 and 2, namely $\left[\mathrm{Cu}_{14} \mathrm{PdH}_{2}\left(\mathrm{~S}_{2} \mathrm{CNH}_{2}\right)_{6}\left(\mathrm{C}_{2} \mathrm{Ph}\right)_{6}\right]$ (1') and $\left[\mathrm{Cu}_{14} \mathrm{PdH}_{2}\left(\mathrm{~S}_{2} \mathrm{PH}_{2}\right)_{6}\left(\mathrm{C}_{2} \mathrm{Ph}\right)_{6}\right]$ (2'). Their optimized geometries were found to be of exact $C_{i}$ and approximate $S_{6}$ symmetry. Their metric data are in a satisfying agreement with their single crystal X-ray counterparts in $\mathbf{1}$ and 2 (Table 1). Their large
HOMO-LUMO gaps (3.50 and $3.38 \mathrm{eV}$ for 1' and 2', respectively) are typical for stable $\mathrm{Cu}(\mathrm{I})$ hydride NCs. ${ }^{[19]}$ The Kohn-Sham orbital diagram of $\mathbf{1}^{\prime}$ is shown in Figure S19. The highest occupied levels have a large $3 \mathrm{~d}(\mathrm{Cu})$ character with little $\mathrm{Pd}$ participation, except for the HOMO which has both significant $\mathrm{Cu}$ and $\mathrm{Pd}$ character. The LUMO and LUMO+2 are delocalized over the whole cluster, except on the hydrides. A natural atomic orbital (NAO) population analysis led to copper atomic charges indicative of $\mathrm{Cu}(\mathrm{I})$ oxidation state $(+0.77$ and +0.83 for the two types of $\mathrm{Cu}_{\text {ico }}$ and +0.66 for $\mathrm{Cu}_{\text {cap }}$ ). The small values of $\mathrm{Cu}-\mathrm{Cu}$ Wiberg indices (avg. $=0.040$, see also Table 1 ) are consistent with this view of weakly interacting $\mathrm{Cu}(\mathrm{I})$ centres, as found in other $\mathrm{Cu}(\mathrm{I})$ polyhydride clusters. ${ }^{[19]}$ The $\mathrm{Pd}-\mathrm{Cu}$ Wiberg indices (avg. $=0.059$ ) are also indicative of weak interactions. Contrarily to that of $\mathrm{Cu}$, the Pd NAO charge is fairly negative $(-0.68)$, as well as that of the hydrides $(-0.55)$. As compared to the $\mathrm{Cu}-\mathrm{H}$ Wiberg indices (avg. $=0.060$ ), their $\mathrm{Pd}-\mathrm{H}$ counterparts have much large values (0.226), indicating significant covalent bonding. As a whole, these data are consistent with the view of a linear $\left[\mathrm{PdH}_{2}\right]^{2-}$ anion encapsulated within a $\left[\mathrm{Cu}_{14}\right]^{14+}$ cage. For the sake of comparison, calculations at the same level of theory on the free 14-electron $\left[\mathrm{PdH}_{2}\right]^{2-}$ complex led to $\mathrm{Pd}-\mathrm{H}$ distances, Wiberg indices and Pd NAO charge of $1.700 \AA, 0.535$, and -0.92 , respectively. These values support the view of anionocovalent interaction between $\left[\mathrm{PdH}_{2}\right]^{2-}$ and its cage, with a moderate but non-negligible anion-cation electron transfer of $0.23 \mathrm{e}(0.18 \mathrm{e}$ in 
the case of $\left.2^{\prime}\right)$. It is noteworthy that the $\left[\mathrm{PdH}_{2}\right]^{2-}$ anionic complex is known to exist in the solid state, for example in $\mathrm{A}_{2} \mathrm{PdH}_{2}(\mathrm{~A}=\mathrm{Li}$ $\mathrm{Na}) \cdot{ }^{\left[{ }^{[8,21]}\right.}$ In these ternary phases, the $\mathrm{Pd}-\mathrm{H}$ distances lie in the range $1.64-1.68 \AA^{[21]}$

TD-DFT calculations on 1' found the simulated low-energy band centered around $460 \mathrm{~nm}$, i.e. substantially blue-shifted with respect to experiment (Figure S20). It is associated with two nearly degenerate transitions, both of HOMO $\rightarrow$ LUMO and $\mathrm{HOMO} \rightarrow \mathrm{LUMO}+2$ character, i.e. of dominant MLCT nature. The intense high-energy band is also of MLCT nature.

Herein, we report the synthesis, structure and full characterization of two atomically precise, palladium-alloyed copper hydride clusters, namely $\left[\mathrm{PdH}_{2} \mathrm{Cu}_{14}(\mathrm{dtc} / \mathrm{dtp})_{6}(\mathrm{C} \equiv \mathrm{CPh})_{6}\right]$ $\left(\mathrm{dtc}=\mathrm{S}_{2} \mathrm{CN}^{n} \mathrm{Bu}_{2}, \mathrm{dtp}=\mathrm{S}_{2} \mathrm{P}\left(\mathrm{O}^{\prime} \mathrm{Pr}\right)_{2}\right)$. The copper atoms display a $D_{3 d}$ bicapped icosahedron, the center of which is occupied by $\mathrm{Pd}$. The two hydrides strongly bonded to $\mathrm{Pd}$ in a linear fashion are also encapsulated within the $\mathrm{PdCu}_{14}$ core, supporting the view of a 14-electron $\left[\mathrm{PdH}_{2}\right]^{2-}$ unit encapsulated in a $\left[\mathrm{Cu}_{14}\right]^{14+}$ cage. As a result, $\mathrm{Pd}$ has the highest coordination number (14), hitherto unknown in literatures. UV-Vis study shows that $\mathbf{1}$ is more stable than 2 in solutions. The emission spectrum of $\mathbf{1}$ is blue-shifted with respect to that of $\mathbf{2}$. Isolation of these novel hydride NCs from pure copper hydrides creates a new frontier in the synthesis of bimetallic species. Such insights are critical for designing novel alloy nanoparticles with enhanced synergistic properties for potential applications in catalysis, energy, and sensing. Future works will direct onto the utilization of new $\mathrm{Pd}$ $\mathrm{Cu}$ NCs in energy storage such as electro-catalytic hydrogen evolution reaction (HER). ${ }^{[22]}$

\section{Acknowledgements}

This work was supported by the Ministry of Science and Technology in Taiwan (MOST 108-2923-M-259-001), the France-Taiwan ANR-MOST 2018 program (project Nanoalloys) and the GENCI French national computer resource center (grant A0030807367). Single crystal neutron diffraction used resources at the Spallation Neutron Source, a DOE Office of Science User Facility operated by the Oak Ridge National Laboratory, under Contract No. DE-AC05-00OR22725 with UT-Battelle, LLC.

Keywords: bicapped icosahedra $\cdot$ nanoclusters $•$ bimetallic• copper $\cdot$ neutron diffraction

[1] a) S. Sharma, K. K. Chakrahari, J.-Y. Saillard, C. W. Liu, Acc. Chem. Res. 2018, 51, 2475-2483; b) I. Chakraborty, T. Pradeep, Chem. Rev.2017,117, 8208-8271; c) R. Jin, C. Zeng, M. Zhou, Y. Chen, Chem. Rev.2016, 116, 10346-10413.

[2] a) R. Jin, K. Nobusada, Nano Research. 2014, 7, 285-300; b) K. R. Krishnadas, A. Ghosh, A. Baksi, I. Chakraborty, G. Natarajan, T. Pradeep, J. Am. Chem. Soc.2016, 138, 140-148.

[3] a) M. S. Bootharaju, C. P. Joshi, M. R. Parida, O. F. Mohammed, O. M. Bakr, Angew. Chem. Int. Ed.2016, 55, 922-926; b) R. P. B. Silalahi, K. K. Chakrahari, J.-H. Liao, S. Kahlal, Y.-C. Liu, M.-H. Chiang, J.-Y. Saillard, C. W. Liu, Chem. Asian J.2018,13,500-504.

[4] N. Barrabes, B. Zhang, T. Burgi, J. Am. Chem. Soc.2014, 136, 14361-14364.

[5] P.Reyes, A. Figueroa, G.Pecchi,J. L.G.Fierro, Catal. Today. 2000, 62, 209-217.
[6] J. A.Anderson,M. Fernandez-Garcia, G. L.Haller,J. Catal.1996, 164,477-483.

[7] C. A.Leon y Leon, M. A.Vannice,Appl. Catal. 1991,69, 305-321.

[8] a) X.Nie, X.Jiang, H.Wang, W.Luo, M. J.Janik,Y.Chen, X.Guo, C.Song, ACS Catal.2018, 8, 4873-489; b) L.Liu,F. Fan, Z.Jiang, X.Gao, J.Wei, T.Fang,J. Phys. Chem. C 2017,121, 26287-26299.

[9] I. M.Saaid,A. R. Mohamed,S.Bhatia,J. Mol. Catal.A: Chem.2002,189, 240-250.

[10] P.-P.Du, X.-C.Hu, X.Wang, C.Ma, M.Du, J.Zeng, C.-J. Jia, Y.-Y.Huanga, R.Si, Inorg. Chem. Front.2017,4, 668- 674.

[11] E.Florez, F.Mondragon,P.Fuentealba,J.Phys. Chem. B.2006,110, 13793-13798.

[12] a)K. K.Chakrahari, J.-H.Liao, S.Kahlal, Y.-C.Liu,M.-H.Chiang,J.Y.Saillard,C. W.Liu,Angew. Chem. Int. Ed.2016, 55, 14704-14708; b) K. K.Chakrahari, R. P. B.Silalahi, J.-H.Liao, S.Kahlal, Y.-C.Liu, J.-F.Lee, M.-H. Chiang, J.-Y. Saillard, C. W. Liu, Chem. Sci.2018, 9, 6785-6795 c) Y.-R. Lin, P. V. V. N. Kishore, J.-H. Liao, S. Kahlal, Y.-C. Liu, M.-H. Chiang, J.-Y. Saillard, C. W. Liu, Nanoscale.2018, 10, 6855-6860.

[13] a) W.-T. Chang, P.-Y. Lee, J.-H. Liao, K. K. Chakrahari, S. Kahlal, Y.-C. Liu, M.-H. Chiang, J.-Y. Saillard, C. W. Liu, Angew. Chem. Int. Ed.2017 56, 10178-10182; b) W.-T. Chang, S. Sharma, J.-H. Liao, S. Kahlal, Y.C. Liu, M.-H. Chiang, J.-Y. Saillard, C. W. Liu, Chem. Eur. J. 2018, 24, 14352-14357.

[14] a)S. L. Christensen, M. A. MacDonald, A. Chatt, P. Zhang, H. Qian, R. Jin, J. Phys. Chem. C.2012, 116, 26932-26937;b) S. Wang, Y. Song, S. Jin, X. Liu, J. Zhang, Y. Pei, X. Meng, M. Chen, P. Li, M. Zhu, J. Am Chem. Soc.2015, 137, 4018-4021;c) C. Yao, Y.-J. Lin, J. Yuan, L. Liao, M. Zhu, L.-H. Weng, J. Yang, Z. Wu, J. Am. Chem. Soc.2015, 137, 15350-15353

[15] a)Y. Negishi, K. Munakata, W. Ohgake, K. Nobusada, J. Phys. Chem Lett. 2012, 3, 2209-2214; b) W. Kurashige, K. Munakata,K. Nobusada Y. Negishi,Chem. Commun.2013, 49, 5447-5449;c) H. Yang, Y. Wang, J. Yan, X. Chen, X. Zhang, H. Hakkinen,N. Zheng, J. Am. Chem. Soc.2014, 136, 7197-7200.

[16] a)J. Jia, Q. Wang, J. Am. Chem. Soc.2009, 131, 16634-16635;b) T. Udayabhaskararao, Y. Sun, N. Goswami, S. K. Pal, K. Balasubramanian, T. Pradeep, Angew. Chem. Int. Ed. 2012, 51 2155-2159;c) X. Pei, Y. Yang, Z. Lei, Q.-M. Wang, J. Am. Chem. Soc.2013, 135, 6435-6437;d) S. Wang, X. Meng, A. Das, T. Li, Y. Song, T. Cao, X. Zhu, M. Zhu, R. Jin,Angew. Chem. Int. Ed.2014, 53, 23762380.

[17] J. Yan,H. Su, H. Yang, S. Malola, S.Lin, H.Ha $\square$ kkinen, N. Zheng, J. Am. Chem. Soc.2015, 137, 11880-11883.

[18] D. Noréus, K. W. Tornroos, A. Borje, T. Szabo, W. Bronger, H. Spittank, G. Auffermann, P. Muller, J. LessCommon Met.1988, 139, 233-239.

[19] a) P. V. V. N. Kishore,J.-H. Liao, H.-N. Hou, Y.-R. Lin, C. W. Liu, Inorg. Chem.2016, 55, 3663-3673;b) R. S. Dhayal, J.-H. Liao, Y.-R. Lin, P.-K. Liao, S. Kahlal, J.-Y. Saillard, C. W. Liu, J. Am. Chem. Soc.2013, 135 4704-4707; c) J.-H. Liao, R. S. Dhayal, X. Wang, S. Kahlal, J.-Y. Saillard, C. W. Liu, Inorg. Chem.2014, 53, 11140-11145; d) R. S. Dhayal, J.-H. Liao, S. Kahlal, X. Wang, Y.-C. Liu, M.-H. Chiang,W. E. Van Zyl, J.-Y. Saillard, C. W. Liu, Chem. Eur. J.2015, 21, 8369-8674; e) R. S. Dhayal, J.-H. Liao, X. Wang, Y.-C. Liu, M.-H. Chiang,S. Kahlal, J.Y.Saillard, C. W. Liu, Angew. Chem. Int. Ed.2015, 54, 13604-13608; f) P.-K. Liao, C.-S. Fang, A. J. Edwards, S. Kahlal, J.-Y. Saillard, C. W. Liu, Inorg. Chem. 2012, 51, 6577-6591.

[20] L. He, J.Yuan, N. Xia, L. Liao, X. Liu, Z. Gan, C. Wang, J. Yang, Z. Wu, J. Am. Chem. Soc.2018, 140, 3487-3490.

[21] a) K. Kadir, D. Noréus, Z. Phys. Chem. 1989, 163, 23-232; b) K. Kadir, M. Kritikos, D. Noréus, A. F. Anderson, J. LessCommon Met. 1991, 172-174, 36-41.

[22] Q. Tang, Y. Lee, D.-Y. Li, W. Choi, C. W. Liu, D. Lee, D.-e. Jiang, J. Am. Chem. Soc.2017, 139, 9728-9736. 


\section{COMMUNICATION}

A unique methodology was used to synthesize atomically precise palladium-alloyed copper hydride clusters. X-ray and neutron diffraction revealed that a 14electron $\left[\mathrm{PdH}_{2}\right]^{2-}$ unit is ionocovalently encapsulated within a bicapped icosahedral $\left[\mathrm{Cu}_{14}\right]^{14+}$ cage and, as a result, the central $\operatorname{Pd}(0)$ adopts the coordination number of 14 .
Kiran Kumarvarma Chakrahari, Rhone P. Brocha Silalahi, Tzu-Hao Chiu, Xiaoping Wang, Nadia Azrou, Samia Kahlal, Yu-Chiao Liu, Ming-Hsi Chiang, Jean-Yves Saillard, ${ }^{*}$ and C. W. Liu *

Page No. - Page No.

Synthesis of Bimetallic Copper-Rich Nanoclusters Encapsulating a Linear Palladium Dihydride Unit 